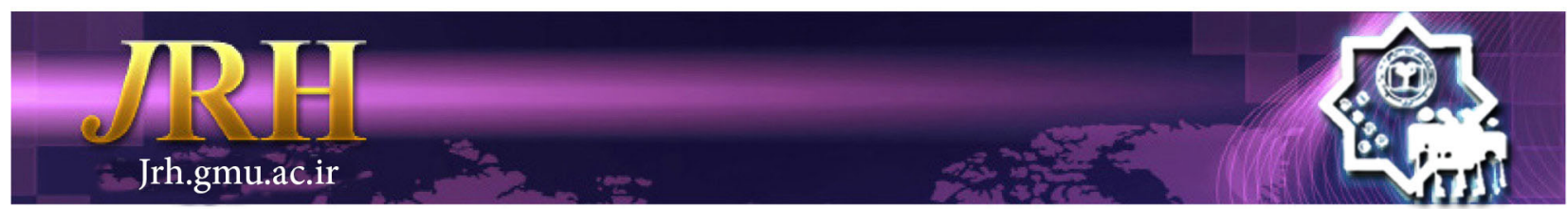

\title{
The relation of attachment styles and problem solving skills to resiliency in treatment-seeking substance dependents
}

Sharife Lovimi ${ }^{1}$, Farideh Nazarzadeh ${ }^{1}$, Fateme Moini ${ }^{1}$, Amir Aminyazdi ${ }^{1}$, Morteza Rostaee ${ }^{1}$

\author{
Journal of Research \& Health \\ Social Development \& Health Promotion \\ Research Center \\ Vol. 8, No. 3, May \& Jun 2018 \\ Pages: $210-217$ \\ DOI: $10.29252 / j r h .8 .3 .210$ \\ Original Article
}

1. Department of Psychology, School of Education Sciences, Ferdowsi University, Mashhad, Iran

Correspondence to: Farideh Nazarzadeh, Department of Psychology, School of Education Sciences, Ferdowsi University, Mashhad, Iran Email: Nazarzadeh1986@gmail.com

Received: 15 Dec 2013

Accepted: 9 Mar 2014

How to cite this article: Lovimi S, Nazarzadeh F, Moini F, Aminyazdi A, Rostaee M. The relation of attachment styles and problem solving skills to resiliency in treatmentseeking substance dependents. $J$ Research Health2018; 8(3): 210- 217.

\begin{abstract}
A new direction in the prevention of drug use is the identification of protective factors. One of the protective factors is the resilience that refers to the process of returning to normal functioning after a stressful event. The present study investigates the relation of attachment styles and problem solving skills to resiliency in treatment-seeking substance dependents referring to the treatment clinics. The study population were drug addicts who had referred to addiction treatment clinics of Ahwaz city. The participants included 186 men and women with drug addiction who were selected by convenience sampling method. Data were collected by using adult attachment style questionnaire, Connor and Davidson Resiliency Scale, and the scale of the problemsolving developed by Cassidy and Long. The results indicated a positive correlation between secure attachment and resilience. They also showed a positive correlation between problem solving skills and resiliency. Results of the regression analysis indicated that attachment style and problem solving can predict the resiliency with 5\% variance. Having beliefs about solving life's problems along with a secure attachment style can increase people's resiliency. This can be used by treatment centers as an important aspect in training patients how to solve the problems and deal with the issue of drug addiction.
\end{abstract}

Keywords: Problem Solving, Substance Dependency, Resilience

\section{Introduction}

Drug dependency and addiction is one of the major problems that most societies are faced with, and it causes them to spend a lot of money. Every year, a large number of drug-dependent people lose their lives as a result of direct and indirect consequences of substance abuse [1]. Based on some reports in our country, there are approximately 4 million addicts and in fact, one of the main problems in our society is addiction and dependency to substances [2]. Preventing from this problem requires identifying the risk and protective factors against substance dependency. Nowadays, in research and clinical fields, instead of decreasing risk factors, the emphasis is on the protective factors in the risky and also healthy population [3].

Research observations have indicated that one of the protective factors is resiliency, which its impression has been confirmed in many researches dealing with addiction threats and problems. Resiliency is a person's capability to create mental-biological balance in dangerous conditions [4]. In other words, resiliency is the positive compatibility in response to unpleasant and horrible conditions. The observations have shown that resilient people 
may less get attracted to risky behaviors such as drug abuse [2].

A special attention has been paid to resiliency in developmental psychology, family psychology and mental health [5]. Seidi et al. have defined the resiliency as "a process, capability or outcome of successful compatibility with threatening conditions". Resiliency isa dynamic process and has a multi-dimensional structure; it is a result of bilateral contact and interaction between individuals and their social environment (family, coevals, school, and society) [5]. Some researches in the field of resiliency show that optimism, finding the meanings in negative experiences, looking at negative experiences from positive perspectives and regarding them as essential experiences of life, believing in the existence a superior power, and having problem solving skills, all have a high correlation with resiliency [6].

One of the factors that can influence people's resiliency is attachment styles in individuals. Attachment is a stable emotional relationship that a person creates with someone else. Hence, attachment is reflected through behaviors that ease the proximity and contact. Attachment builds the foundation of healthy emotional and social development during adulthood. In fact, human's attachments play a vital role in his/ her life. Attachment styles which are referred to attachment orientation or attachment patterns [7] specify the emotional cognitive rules and strategies which can regulate emotional reactions in people during interpersonal relationships $[8,9]$. Attachment styles are integrated and they are relatively stable patterns of emotion and behavior, which appear in close relationships" [10]. Ainsworth succeeded to identify two types of attachments; secure and unsecure. Unsecure attachment style includes two types of preventive and ambivalent. People with secure attachment style do not fear of dangers, because they do not feel alone in risky situations; they tend to create intimate and positive relationships with others and in comparison with people who have unsecure attachment style, they have higher selfesteem [11].

The conducted researches in this area have revealed that between subjects who had secure attachment style and a group with unsecure attachment style, there is a significant difference in terms of being hopeful and having positive emotions while the positive attitude and hope to surrounding world were in line with resiliency [12]. In a research, Gronorth showed that people with different attachment styles act differently in response to the environmental distress. Also, Mikoleniser and Shaver, in their investigation, concluded that unsecure attachment may result in conduct disorder and social deviance or felonious and criminal behaviors. People who have anxious attachment, as a naive method for attention attraction and extreme care, engage in conduct disorder and crime. In addition, unsecure attachment has a relation with high level of alcohol use, smoking and drug abuse in young adolescents [13].

Also, according to various investigations, one of the characteristics of resilient individuals is having the problem-solving skills [14]. Problem solving is referred to the cognitive, behavioral and attitudinal process of a person, by which a person tries to determine, discover and invent adaptive and effective confronting strategies against problematic situations in routine life [15]. Problem solving method includes high level skills of thinking such as mental visualization, abstraction, perception and understanding, manipulation, argumentation, analysis, conclusion and generalization that must be well managed. Disabled people in problem solving, by taking ineffective solutions, such as substance abuse for relaxation, smoking for attention attraction and leaving school due to the disability in meeting educational problems, not only make the problem more sophisticated and worse, but also may be exposed to death risk (e.g. suicide or acting out for suicide) [16].

In relation with accomplished investigations and researches on the role of problem solving methods in resiliency, Shure [17] showed that people who have weak problem solving skills, may show impulsive behaviors and become hopeless, desperate and aggressive when 
facing problems and in order to prevent from problematic situations, they detach and abdicate from the society. Wolff [18], Tugade and Fredrickson [20], Inzlicht, Aronson, Good and Mckay [19] in their researches have emphasized on the role of resiliency in mental health and have expressed that resilient people can keep their mental health and compatibility in adverse conditions when experiencing a negative emotion and they also have stated that some skills, including problem solving, self-efficacy and social support are involved in this issue.

Generally, by looking at the phenomenon of the addiction with a psychological perspective, it can be referred as an illness that should be treated and definitely, in order to oppose every illness, first, the contexts of appearance of that illness should be found and prevented. Thus, these kinds of studies and researches are required to better recognize the effective factors in addiction, to find its origin and finally, to pave the way for reform and education. Although many researches have been conducted in relation with resiliency, a few studies have been conducted in this field from the standpoint of attachment and problem solving, inside and outside the country. Hence, the aim of the present work was to assess the relationship of attachment styles and problem solving skills with resiliency among treatmentseeking substance dependents.

\section{Method}

The present study was a cross-sectional research, which has been conducted to assess the relationship of attachment styles and problem solving skills with resiliency in treatment-seeking substance dependents. The study population was all substance dependents who were willing to quit their addiction referring to the treatment clinics, affiliated to Ahwaz Welfare organization in summer and fall 2015. The sample size of the research based on the Morgan's formula included 186 persons out of a crowd of 300 that were selected using convenience method of sampling. In order to collect data, after receiving a permission from the university and Ahwaz Welfare organization, by in-person referring to addiction treatment centers of Ahwaz
Welfare organization and then expressing the aim of the study and obtaining participants' consent for attending in this investigation, the ASQ, CD-RISC, and the scale of problem solving methods were given to every person individually. They were guided to correctly respond to the questions.

In this research tools included:

Adult Attachment style Questionnaire (ASQ): This questionnaire was created by Hazan and Shure to measure a person's attachment styles. The questionnaire is practicable individually or in group. It includes two sections: in the first section (ASQ1), three main paragraphs are expressed in descriptive sentences and the participants needs to specify his/her responses on a 7-point Likert scale in range of "strongly disagree" to "strongly agree". In fact, this scale determines to what extenta description is in agreement with the character of the participants. In the second section (ASQ2), once again, the same descriptions are expressed, but this time, the participants should express his/her similarity with one of the descriptions by choosing only one of them. The test-retest reliability was 0.6 for ASQ1 and 0.7 for ASQ2. In Pakdaman's research, the reliability of this test was obtained using test-retest method on a 100-person sample with one month interval for distress-ambivalence, preventive, and secure attachment styles equal to $0.72,0.56$, and 0.37 , respectively, and the value of Cronbach's alpha was obtained as 0.79 , which showed a relatively high reliability. The validity of this questionnaire in a sample of 100 participants was investigated based on the divergent validity, and the results revealed that three descriptions of the questionnaire can measure three separate contents. The correlation of the secure attachment with preventive attachment was 0.1 , the correlation of the secure attachment with distress ambivalent attachment was 0.54 , and the correlation of the preventive attachment with distress ambivalent attachment was 0.14 , which were very low. In behzadipour's study, the reliability coefficient using retest method over one month interval on 30 participants was calculated as 0.93 for 
the first style, 0.89 for the second, and 0.92 for the third one, and it was also observed at 0.95 for the second scale (ASQ2) [6].

Connor and Davidson Resiliency Scale (CD-RISC): This scale was created through reviewing research resources in a resilience field by Connor and Davidson. The psychiatric properties of this scale have been assessed in 6 groups as follows: the general population, participants who referred to primary care sector, psychiatric outpatients, people with generalized anxiety disorder and two groups of patients with post-traumatic stress. The providers of this scale believed that the scale could well differentiate the resilient people from intolerant ones, in both clinical and non-clinical groups. This questionnaire has 25 items that are scored on a Likert scale between (totally incorrect) and (totally correct). The maximum score is 100 and the minimum is zero. This scale has been normalized by Mohammadi in Iran. In order to determine its validity, first the correlation of each item with the total score of the scale was calculated and then, factor analysis was used. Jafarihas reported Cronbach's alpha coefficient of 0.88 for this scale [5].

Problem Solving Method Scale: This scale was created by Cassidy and Long in 1996 during two studies. This scale includes 24 questions and is built from 6 components, while each factor involves 4 items. The failure component indicates general failure of a person in problematic situations. The control subscale of problem solving scale reflects the dimension of internal-external control in problematic situations. The creativity subscale indicates planning and considering various solutions. The confidence subscale in problem solving indicates the belief in person's capability for problem solving. The preventing subscale reflects the willingness to pass problems instead of confronting them. The approach subscale indicates the positive attitude toward problems and the willingness to confront them. All the obtained alpha coefficients for these subscales were over 0.50 , which Nonaly has argued that, this value is sufficient for research aims. Moreover, the average internal correlation of the items show that they are homogenous sets and it can be argued that they have the required validity (Cassidy and Long). The scale of problem solving method has been translated and assessed by Mohammadi [21]. In the present study, data were analyzed using SPSS-16. Beside the descriptive criteria, in order to investigate the relationship of attachment styles and problem solving with resilience, Pearson's correlation test and regression analysis were used. $\mathrm{p}<0.05$ was considered statistically significant.

\section{Results}

The sample consisted of 186 treatmentseeking addicted persons ( $86 \%$ men and 16\% women), whose education level was between Diploma and Master degree and their age range was 18 to 64 years. The descriptive data are provided in Table 1.

Table 1 Demographic information of the participants

\begin{tabular}{clcc}
\hline \multirow{2}{*}{ Sex } & & Frequency & Percentage \\
\cline { 2 - 4 } & Men & 156 & 83.9 \\
& Women & 30 & 16.1 \\
& Total & 186 & 100 \\
\hline \multirow{5}{*}{ Education } & Variable & Frequency & Frequency Percentage \\
\cline { 2 - 4 } & & & \\
& Diploma & 55 & 29.6 \\
& Associate Degree & 24 & 12.9 \\
& Bachelor Degree & 9 & 4.8 \\
& Master Degree & 3 & 1.6 \\
& Total & 183 & 100 \\
\hline
\end{tabular}


In this study, the correlation of attachment styles and problem solvingskills with resilience was investigated among treatment- seeking substance dependents. Table 2 shows the obtained results on the correlation test.

Table 2 The correlation between attachment styles (secure and unsecure), problem solving, and resilience

\begin{tabular}{clccc}
\hline & & $\begin{array}{c}\text { Unsecure } \\
\text { Attachment }\end{array}$ & $\begin{array}{c}\text { Secure } \\
\text { Attachment }\end{array}$ & $\begin{array}{c}\text { Problem Solving } \\
\text { Method }\end{array}$ \\
\hline \multirow{3}{*}{ Resilience } & Pearson's Correlation & -0.206 & 0.373 & 0.219 \\
& Significance level & 0.05 & 0.00 & 0.003 \\
& Number of respondents & 186 & 185 & 186 \\
\hline
\end{tabular}

Based on Table 2, there was a significant relationship between secure attachment style and resilience in addicts $(\mathrm{p}<0.05, \mathrm{n}=186$, $\mathrm{r}=0.373$ ). Also, Table 2 reveals that there was a correlation between resilience and unsecure attachment style by giving $r=-0.206$. The significance level of this correlation was lower than 0.05 ; therefore, there was a significant negative relationship between unsecure attachment style and resilience $(\mathrm{p}<0.05$, $\mathrm{n}=186, \mathrm{r}=-0.206$ ).

According to Table 3, there was also a correlation between resilience and problem solving method $(\mathrm{r}=0.219)$. The significance level of this correlation was lower than 0.05 and hence, there was a significant relationship between problem solving and resilience $(\mathrm{p}<0.05, \mathrm{n}=186, \mathrm{r}=0.219)$.

Table 3 The regression coefficients of resilience based on attachment and problem solving styles

\begin{tabular}{lccccc}
\hline Variables & $\mathrm{B}$ & Standard Deviation & & $\mathrm{t}$ & Significance \\
\hline Secure attachment style & 0.33 & 0.28 & 0.088 & 1.20 & 0.23 \\
Problem Solving Method & 0.90 & 0.34 & 0.194 & 2.63 & 0.00 \\
\hline
\end{tabular}

In order to investigate the role of attachment styles and problem solving skills in resilience, the simultaneous regression analysis was performed to show the value of correlation factor between the two predictor variables and resilience (0.22). Based on the value of $\mathrm{R}^{2}$, which was obtained as 0.052 , it can be said that $5.2 \%$ of the resilience scores' variances were explained by attachment styles and problem solving methods. Also, the results revealed that problem solving method was able to explain $19 \%$ of the resilience variance; it means that the participants whose resilience was higher obtained higher scores on problem solving methods. But, secure attachment style $(\mathrm{p}=0.23$, $\mathrm{t}=1.20$ )was able to justify only $8 \%$ of the resilience score variance.

\section{Discussion}

On one hand, worrying reports concerning substance abuse and on the other hand, request of families and society for drug use prevention both indicate that the society needs special interventions and trainings in this regard. Thus, identifying effective factors on preventing addiction can help prevent substance abuse. Therefore, the present work was carried out to assess the relationship of attachment styles and problem solving skills with resilience, which is one of the important factors in confronting the addiction issue.

The results of the study showed that there is a significant positive relation between secure attachment style and resilience. This result is in agreement with the results of the researches carried out by Caspers, Cadort, Douglas et al. [22] and Mcnally, Palfai, Levine, More, et al. [23]. People, who have secure attachment style, have higher levels of self-confidence. In fact, these people have higher resilience in comparison with those who have unsecure attachment. These people have nurtured in themselves some indicators such as selfesteem, hope, and optimism from childhood due to the secure attachment style, and they are less likely to attract to unreasonable methods such as substance abuse. Instead, in solving life problems, these people refer to 
their personality indicators rather than mental factors like substance abuse [16]. Also, in the present research, it was shown that there is a significant negative relation between unsecure attachment style and resilience. These people have less self-confidence and less secure feeling toward surrounding environment and those around them. Unsecure people, due to the unsecure design formed in their mind, avoid from confronting the problems and as a result, are more fragile and vulnerable to the problems and inevitable risks of life. Thus, it seems that these people are more likely to use unreasonable solutions such as substance abuse to solve their problems [16]. The result of this research is in agreement with those obtained by Bottonari, Roberts, Kelly and Ciesla [12] and Stansfeld, Head, Bartley and Fonagy [24].

Moreover, our results showed that there is a positive significant relationship between problem solving methods and resilience, and it was also shown that the problem-solving methods can predict the resilience in people. Problem solving skills have been expressed as a basic component in the resilience of people in research of Varend, Karmzy, Rotter, and Vaisaxon [25]. This result is consistent with obtained results of Shure [17]. The latter study showed that people, who have good problem solving skills, can choose reasonable solutions in consecutive steps for their problems. They can guess the potential obstacles in problem solving and consider actions in order to meet them. Also, Khoshnavay Foumani, Fatemi, Behbahani and Hosseini [25] in their research showed a significant relationship between problem solving skills and using Ecstasy by young adolescents. Their results revealed that young adolescents, who had good skills of problem solving, were not Ecstasy consumers, while the maximum amount of use was observed among young adolescents, who had low problem-solving skills. The findings of the present work are consistent with those of Mohammadi's study [26], which showed that the problem solving skill in comparison with other individual variables is a more important predictive factor for resilience. In fact, gaining problem solving skills has an important role in mental health, especially when a person encounters unpleasant events and life problems. Attachment is related to experiencing life affairs. Experience increases the ability to solve problems. When the ability to solve problems increases, naturally, stronger self-efficacy and self-confidence can be nurtured that promotes people's psychological resilience against life problems [25].

The low number of participants and lack of access to all treatment-seeking addicts, because they were seeking for treatment through methods other than referring to treatment clinics, can be mentioned as the limitations of the present research. It is suggested to investigate other variables associated with family, such as nurturing, cognitive, and meta-cognitive variables related to resilience in treatment-seeking addicts in future works.

\section{Conclusion}

In general, the results of the current study showed that attachment styles and problem solving skills were significantly correlated with resilience. People with strong problem solving skills try to suitably solve their problems and their belief in solving problems in life increases the amount of resilience in them for facing problems. It can be used as an important tool by rehabilitation centers in training addicted patients how to solve the problems and deal with the issue of addiction. Also, the formation of secure attachment style causes a person to have a positive attitude toward surrounding events, which is of determinative factors in people's tolerance in confronting issues.

\section{Acknowledgements}

The authors would like to thank addiction treatment clinics affiliated to Ahwaz welfare organization and all participants in this study for their kind collaborations.

\section{Contribution}

Study design: SHL, FN, FM, AA 
Data collection: SHL, FM, MR

Data analysis: SHL, FN, FM

Manuscript preparation: SHL, FN, FM

\section{Conflict of Interest}

"The authors declare that they have no competing interests."

\section{Funding}

The author (s) received no financial support for the research, authorship and/or publication of this article.

\section{Reference}

1- Martin PR, Weinberg BA, Bealer BK. Healing addiction: An integrated pharmacho-psychological approach to treatment. United States of America: John Wiley \& Sons; 2007.

2- Hosseini Al-madany SA, Ahadi H, Karimi Y, Bahrami H, Mazdyan A. Compare resiliency, identity styles, spirituality and perceived social support in addicted, none addicted, and improved. Journal of Addiction research2012; 6(21): 64-4.

3- Connor KM, Davidson JR. Development of a new resilience scale: the Connor-Davidson resilience scale (CD-RISC). Depress Anxiety2003; 18(2): 76-82.

4- Werner EK, Smith RS. Overcoming the odds: high risk children from birth to adulthood. Ithaca, New York: Cornell University press; 2000.

5- Seidi MS, Pourebrahim T, Bagherian F, Mansouri

L. The relationship between spirituality family with resiliency The mediation of family relationship quality. Psychological Models2011; 2(5): 63-79.

6- Hashemi L, Joker B. The relationship between spiritual transcendence and resilience in students. Educational Psychology Studies2011; 8(13): 123-42.

7- Davis D. Child development: a practitioner guide. New York: The Guilford press; 2004.

8- Besharat MA, Ghafouri B, Rostami R. A comparative study of attachment styles in persons with or without substance use disorders. Research in Medicine2007; 31(3): 265-71.

9- Kamel Abbasi A. The relationship between attachment styles and emotional intelligence with marital satisfaction.

[Thesis]. Faculty of Psychology and Educational Sciences. Mashhad: Ferdowsi University 2011.

10- Platts H, Tyson M, Mason O. Adult attachment style and core beliefs: are they linked? Clin Psychol Psychother2002; 9: 332-48.

11 Bowlby J. Attachment and loss: vol. II. Separation: Anxiety and Anger. New York: Basic Books; 1973.

12- Bottonari KA, Roberts JE, Kelly MA, Kashdan TB,
Ciesla JA. A prospective investigation of the impact of attachment style on stress generation among clinically depressed individuals. Behav Res Ther2007; 45(1): 179-88.

13- Mikulincer M, Shaver PR. Attachment in adulthood structure, dynamics, and change. New York London: The Guilford press; 2007.

14- Friborg O, Hjemdel O, Rosenvinge JH, Martinussen $\mathrm{M}$. A new rating scale for adult resilience: what are the central protective resources behind healthy adjustment? Int J Methods Psychiatr Res2003; 12(2): 65-76.

15- Fisher B. Relationship between social problemsolving skill, quality of life and family adjustment in caregiver of children with developmental disability. [dissertations]. Philadelphia College of Osteopathic Medicine, Psychology 2009; 1-188.

16- Chang EC, D’zurillaTJ, Sanna LJ. Social problem solving: theory, research and training. Washington D. C: American Psychological Association; 2004.

17- Shure MB. I can problem: an interpersonal cognitive problem-solving program. Champaign: Research press; 2001.

18- Wolff S. The concept of resilience. Aust $N Z J$ Psychiatry1995; 29(4): 565-74.

19- Inzlicht M, Aronson J, Good C, Mckay L. A particular resiliency to threatening environments. $J$ Exp Soc Psychol2006; 42(3): 323-36.

20- Tugade MM, Fredrickson BL. Resilient individuals use positive emotions to bounce back from negative emotional experiences. J Pers Soc Psychol2004; 86(2): 320-33.

21- Mohammadi F, Sahebi A. Style of problem solving in depressed patients compared with normal subjects. Journal of Psychology2001; 1(3): 33-50.

22- Caspers KM, Cadoret RJ, Douglas L, Yucuis R, Troutman B. Contributions of attachment style and perceived social support to life time use of illicit substances. J Addict Behav2005; 30: 1007-11.

23- Mcually AM, Palfai TP, Levine RV, Moore BM. Attachment dimensions and drinking-related problems among young adults. Addict Behav2003; 28: 115-26.

24- Stansfeld S, Head J, Bartley M, Fonagy P. Social position early deprivation and the development of attachment. Soc Psychiatry Psychiatr Epidemiol2008; 43: 516-26.

25- Seyedfatemi N, Khshnavaye Foomani F, Behbahani N, Hoseini F. Relationship between problem solving skill and ecstasy usage among adolescents. IJPN2013; 1(1): 19-27.

26- Mohammadi M. Factors affecting resilience in individuals at risk for substance abuse. [Thesis]. Tehran: University of Welfare and Tehabilitation Sciences 2005.

27- Cohn DA, Silver DH, Cowan CP, Cowan PA, 
Pearson J. Working models of childhood attachment and

couple relationships. J Fam Issues 1992; 13: 432-49.

Copyright $\odot 2016$ ASP Ins. This open-access article is published under the terms of the Creative Commons Attribution-NonCommercial 4.0

International License which permits Share (copy and redistribute the material in any medium or format) and Adapt (remix, transform, and build upon the material) under the Attribution-NonCommercial terms. 